\title{
Home physical exercise program: analysis of the impact on the clinical evolution of patients with normal pressure hydrocephalus
}

\author{
Programa de exercícios físicos domiciliares: análise do impacto na evolução clínica de \\ pacientes com hidrocefalia de pressão normal
}

Paulo Cesar MODESTO',2, Fernando Campos Gomes PINTO',2

\begin{abstract}
Objective: To present a program of home physical exercises for patients with normal pressure hydrocephalus (NPH) and to evaluate adherence, acceptance and applicability; to verify possible changes in patients with NPH in the home physical exercise program, comparing patients with, and without, a ventriculoperitoneal shunt, regarding gait, quality of life, activities of daily living, static and dynamic balance and its impact on the risks of falling. Methods: This was a controlled clinical trial, with assessments in three moments (0, 10 and 18 weeks) at the home, from October 2015 to November 2017. Fifty-two patients (30 women and 22 men) participated in the study. Results: There was a statistically significant improvement with 10 weeks of home physical exercises for the groups with and without ventriculoperitoneal shunt, respectively, in the sub-items: activities of daily living $p=0.032^{*}, p=0.003^{*}$; static balance $p<0.001^{*}, p<0.001^{*}$; functional capacity $p<0.001^{\star}, p=0.027^{*}$; and dynamic balance and gait $p=0.009^{*}, p<0.001^{\star}$. There was no statistically significant difference for the subitems: quality of life $p=0.695, p=1.000$; and NPH grading scale $p=0.695, p=1.000$, respectively. Conclusion: The developed program of home physical exercise was easily applied and there was good acceptance by most patients with NPH included in the research. There was a statistically significant improvement with the 10 weeks of home physical exercises in the sub-items: activities of daily living, static balance and functional capacity, for both groups. In the sub-item dynamic balance and gait, there was a statistically significant improvement for both groups, but with a higher score for the group with a ventriculoperitoneal shunt. There was no statistically significant difference for the sub-items: quality of life, NPH grading scale and risk of falls, based on the Berg scale.
\end{abstract}

Keywords: Hydrocephalus normal pressure; ventriculoperitoneal shunt; gait; quality of life; physical therapy

\section{RESUMO}

Objetivo: Apresentar um programa de exercícios físicos domiciliares para pacientes com hidrocefalia de pressão normal e avaliar a adesão, aceitação e sua aplicabilidade; verificar possiveis alterações nos pacientes com HPN com o programa de exercícios físicos domiciliares, comparando os pacientes com e sem derivação ventriculoperitoneal, no que diz respeito à marcha, qualidade de vida, atividades de vida diária, equilíbrio estático e dinâmico e sua repercussão nos riscos de queda. Métodos: Trata-se de um Ensaio clínico controlado, com avaliações em três momentos ( 0.10 e 18 semanas) em nível domiciliar, no período de outubro/2015 a novembro/2017. Participaram do estudo 52 pacientes (30 mulheres e 22 homens). Resultados: Houve melhora estatisticamente significante com as dez semanas de exercícios físicos domiciliares para os grupos sem e com derivação ventriculoperitoneal respectivamente, nos subitens: atividades de vida diária $p=0,032 *$ $p=0.003^{*}$, equilíbrio estático $p<0.001^{*}, p<0.001^{*}$; capacidade funcional $p<0.001^{*}, p=0,027 *$; equilíbrio dinâmico e marcha $p=0.009 *$, $p<0.001 *$ Não houve diferença estatística significante para os subitens: qualidade de vida $p=0,695, p=1,000$ e escala de graduação de HPN $p=0,695, p=1,000$. Conclusão: 0 programa de exercícios físicos domiciliares desenvolvido mostrou-se de fácil aplicabilidade e houve boa aceitação para a maioria dos pacientes com Hidrocefalia de Pressão Normal inseridos na pesquisa. Houve melhora estatisticamente significante com as dez semanas de exercícios físicos domiciliares nos subitens: atividades de vida diária, equilíbrio estático e capacidade funcional para ambos os grupos. No subitem equilíbrio dinâmico e marcha houve melhora estatisticamente significante para ambos os grupos, mas com escore maior para o grupo com derivação ventriculoperitoneal. Não houve diferença estatisticamente significante para os subitens: qualidade de vida, escala de graduação de Hidrocefalia de Pressão Normal e risco de quedas baseado na escala de Berg.

Palavras-chave: Hidrocefalia de pressão normal; derivação ventriculoperitoneal; marcha; qualidade de vida; fisioterapia

\footnotetext{
${ }^{1}$ Hospital do Servidor Público Estadual, Programa de Pós-Graduação em Ciências da Saúde, São Paulo SP, Brasil

¿2Universidade de São Paulo, Hospital das Clínicas, Instituto de Psiquiatria, Divisão de Neurocirurgia Funcional, Grupo de Hidrodinâmica Cerebral, São Paulo SP, Brasil
}

Paulo Cesar Modesto iD https://orcid.org/0000-0001-7462-7920; Fernando Campos Gomes Pinto iD https://orcid.org/0000-0003-2384-2190 Correspondence: Paulo Cesar Modesto; Rua Corcovado, 134 / bloco 54 / apto 28; 05038-040 São Paulo SP, Brasil; E-mail: pa.modesto@uol.com.br Conflict of interest: There is no conflict of interest to declare.

Received 14 May 2019; Received in final form 05 August 2019; Accepted 06 August 2019. 
Normal pressure hydrocephalus (NPH) is a neurological disease, characterized by progression of gait apraxia, cognitive alterations and urinary incontinence (known as Hakim-Adams syndrome), associated with ventriculomegaly (detected radiologically) and normal cerebrospinal fluid pressure $e^{1,2,3,4}$.

Normal pressure was first recognized in the 1960s by Hakim and Adams et al., who observed progressive dementia, gait changes, and dilatation of the ventricular system ${ }^{1,5}$.

Idiopathic NPH predominantly manifests itself between the sixth and seventh decade of life. Secondary NPH may also occur in young individuals ${ }^{6}$.

The diagnosis is clinical, corroborated by neuroimaging examinations (magnetic resonance and computed tomography) and functional tests, such as the tap test, infusion test and external lumbar drainage for 72 hours $^{7,89,10,11}$. The classic, and universally-recommended treatment is a ventriculoperitoneal shunt (VPS). The manifestations caused by NPH directly compromise the quality of life, especially the patient's autonomy, but it is important to state that, in most cases, it is reversible with the appropriate treatment, with a combination of surgical and multidisciplinary rehabilitation ${ }^{12}$.

Physiotherapy, as an integral part of this multidisciplinary work, aims to monitor the gait pattern of patients with NPH, as this manifests as the inability to perform a sequence of movements, and the absence of motor and sensory symptoms. Depending on the degree of complexity, patients may need some external support to walk, or may be unable to perform the gait ${ }^{12}$.

Difficulties with day-to-day tasks, such as taking care of personal hygiene, dressing, feeding, or even walking, usually appear slowly at the beginning of the illness, when movements slow down and the balance is impaired. The patient loses the stimuli for performing these activities, becomes discouraged, and generally avoids social activities ${ }^{12}$.

Based on these difficulties, and the large waiting list for rehabilitation of these patients in the respective centers where this research was developed, a program of physical exercises designed to be done at home was developed, with the objective of improving gait pattern, quality of life, activities of daily living, static and dynamic balance, and risk of falling in patients whether they were to undergo VPS or not.

\section{METHODS}

This was a controlled clinical trial, performed at the Cerebral Hydrodynamics Ambulatory Clinic of the Functional Neurosurgery Division, Institute of Psychiatry at the Hospital das Clínicas, with the evaluations performed at home, from October 2015 to November 2017. Fifty-two patients ( 30 women and 22 men) participated in the study.

The study was approved by the Ethics Committee of the Hospital do Servidor Público Estadual, with project approval number 2.647.104, and the Hospital das Clínicas of the Faculty of Medicine of the University of São Paulo, number 2.671.201.

After becoming aware of the study procedures, the volunteers signed the terms of consent form.

\section{Inclusion criteria}

Patients with a diagnosis of idiopathic or secondary NPH, over 18 years of age, of both genders, who had not yet received VPS implantation were included.

\section{Exclusion criteria}

The patients excluded were: those with an inability to walk, who used a walker or cane, with severe labyrinth diseases, psychiatric disorders, Parkinson's disease, malignancy, severe visual acuity limitation, deficits in comprehension of verbal commands, and being in physiotherapeutic treatment or having participated in physiotherapy or a physical conditioning program, in the two months prior to the beginning of this study.

\section{Protocol}

All patients who participated in the study were followed up in the outpatient clinic at the Cerebral Hydrodynamics Service of the Institute of Psychiatry of the Hospital das Clínicas, and were screened after consultation at the Neurosurgery Service. Patients were submitted to VPS implantation over 10 weeks, returning to activities with home physical exercises after medical orientation.

\section{Rating scale}

\section{General evaluation}

After the screening of the participants, an evaluation of the patient's general status was performed, through an interview, where personal data, the patient's history regarding physiotherapy, personal and family history, the evolution of the disease, examinations, and drug treatment were collected.

The evaluation scales are used in clinical practice because they are easy to apply, low cost and dispense with the use of special equipment $t^{12,13}$.

\section{Measure of functional independence}

The Measure of Functional Independence is a selected scale as, in the clinical environment, it is considered complete, due to it covering both motor and cognitive components. It has wide acceptance in the national and international literature, as well as having been validated in different countries ${ }^{14}$.

It meets the criteria of reliability, validity, accuracy, practicality, and facility ${ }^{15}$. Minimum score: 18 points; maximum score: 126 points. 


\section{The Berg balance scale}

This scale, created in 1992 to evaluate static balance in adult patients, is easy to apply and widely used in clinical research, especially in the elderly over 60 years. Translated and adapted to Portuguese in 2004, it demonstrated, in the study, an excellent inter- and intra-observer reliability ${ }^{16,17}$. Minimum score: 0; maximum score: 56 points.

\section{Dynamic gait index}

The Dynamic Gait Index has been widely used in clinical practice to assess dynamic balance and gait. This scale evaluates aspects of the dynamic balance that the Berg Balance Scale does not measure, as well as assessing aspects of gait, such as wandering with head movements or walking through obstacles ${ }^{18}$. Minimum score: 0 ; maximum score: 24 points.

\section{Grading scale of the NPH patient}

The Japanese scale for NPH evaluation, currently, is the most established specific scale for grading the changes resulting from the disease. Created and developed by a scientific research committee, maintained by the Japanese Ministry of Health and Wellness, the scale, called the "Grading Scale for Idiopathic Normal Pressure Hydrocephalus", is very simple and can be applied easily, practically and quickly ${ }^{19-21}$.

It was validated in Brazil in 2014 and is subdivided into three items, each one specific to the classic NPH triad, with five points ranging from 0 to 4 , where 0 indicates less impairment and 4 is the greatest impairment, with a total of 12 points $^{19-22}$.

\section{Quality of life assessment scale in Alzheimer's disease}

Logsdon et al..$^{23}$ (1999, apud Novelli, 2006) created the Quality of Life (QoL)-Alzheimer's Disease scale to be used as a measurement instrument for QoL evaluation in patients with dementia. This instrument comprises 13 items: physical health, disposition, humor, housing, memory, family, marriage, friends, you in general, ability to do tasks, ability to do leisure activities, money, and life in general ${ }^{23,24}$.

The overall score is obtained by summing all 13 items evaluated, with a minimum score of 13 points and a maximum score of 52 points. Higher rates indicate a better QoL.

In the present research, the scale used was translated and adapted cross-culturally to the Brazilian population by Novelli ${ }^{24}$, where in its first version, the elderly person with dementia evaluated their own QoL.

\section{Timed up and Go test}

According to Loth et al. ${ }^{25}$, the Timed Up and Go test is a tool for rapid assessment of functional mobility in the elderly. The patient begins the test sitting on a standard 18-inch chair with a backrest and armrest. At the verbal command "go", they are required to get up from the chair, walk comfortably and safely in a straight line for three meters, turn around, return and sit in the starting position ${ }^{25}$. The test score is based on the time the individual took to perform the task.

\section{Mini-mental state examination}

The Mini-Mental State Examination is a brief clinical assessment of cognitive status change in geriatric patients. This examination is intended to examine temporal and spatial orientation, short-term memory (immediate or attentive), evocation, calculation, praxis, and language and visuospatial skills, and can be used as a screening test for cognitive impairment or as a bedside cognitive assessment ${ }^{26,27}$. Values may vary from 0 to 30 points with the lower the number, the worse the cognitive performance ${ }^{26,27}$.

\section{Home physical exercises training}

The home physical exercises were designed and adapted so that they could be performed independently and safely in the patient's residence, according to the following objectives: to improve the active and passive range of movement; improve static and dynamic balance; improve gait; facilitate activities of daily living such as transfers; provide more body awareness; improve the dissociation of wrists; strengthen the upper and lower limbs (performed lightly and without external resistance).

Patients received the guidelines at the ambulatory clinic and the exercise training was carried out at the residence, where the main researcher, a physiotherapist specialized in neurological rehabilitation, taught, guided and clarified any doubts regarding the exercises, both for the patients and for the companions.

The training consisted of three visits by the researcher to the patient's home, to facilitate the learning of the home exercise program. An adapted exercise booklet was given to all patients, so they could follow each exercise during the home training. The exercises were performed three times a week, with an interval of one day between exercises, until 30 sessions were completed. After the end of each session, the family member or caregiver filled out the exercise diary to confirm adherence to the program (Appendix).

\section{Evaluation period}

Data from the evaluations were collected for all patients, in the following periods:

First evaluation: pretreatment (week 0-baseline); Second evaluation: after 10 weeks of treatment, the VPS was implanted within this period (week 10 post-treatment); Third evaluation: after completion of an additional eight weeks of treatment (week 18 - follow-up).

After 10 weeks of home training, patients were instructed to continue performing the exercises, and then evaluated whether the results obtained in the 10-week period remained similar after an additional eight weeks of training. 


\section{Statistical analysis}

The results are presented in the form of tables and graphs and presented in the form of descriptive analyses of the sample and analyses of the variables between the groups and between the evaluations. Quantitative descriptive variables are shown as average, median and interquartile interval.

To verify which kind of analysis to apply, we verified the normality of the numerical variables, and the lack of adherence to the normal distribution indicated the use of nonparametric tests, with the application of the Kolmogorov-Smirnov test. In the comparisons between the groups (with and without VPS), we used the nonparametric Mann-Whitney tests, and between moments ( 0,10 and 18 weeks), we used the nonparametric Friedman test, with Sidak multiple comparisons when significant.

The significance level adopted for the statistical tests was $5 \%$.

\section{RESULTS}

\section{Sample descriptive analysis}

The sample descriptive analysis is shown in Table 1, where the variables of the 52 patients in the study (baseline assessment data) are described, with regard to age, age at disease onset, mental status, time of disease (years), schooling and gender [ female $(\mathrm{F})$ or male $(\mathrm{M})]$.

Data is expressed as a mean \pm standard deviation; median, interquartile range, percentage (\%), Mini-Mental State Examination, M/F, without VPS: No ventriculoperitoneal shunt; with VPS: with ventriculoperitoneal shunt; n: number of patients. "Mann-Whitney test for comparison of numerical measures between the two groups.

\section{Daily living activity}

In the daily life activities, the Functional Independence Measure scale showed a statistically significant change after the treatment period $(1 \times 2)$ for the group with VPS and the group without VPS. There was no difference after the third evaluation $(2 \times 3$ - follow-up), indicating that there was no loss of gains in activities of daily living two months after the end of treatment for both groups (Figure 1, Table 2).

\section{The Berg balance scale}

The static balance showed a statistically significant change after the treatment period $(1 \times 2)$ for the groups with VPS and without VPS. There was no difference after the third evaluation $(2 \times 3$ - follow-up), indicating that there was no loss of gains two months after the end of treatment for both groups (Figure 2, Table 3).

\section{Dynamic Gait Index}

Dynamic balance and gait showed a statistically significant improvement for both groups, after the treatment period $(1 \times 2)$ for the groups with VPS and without VPS. However, the group with VPS had a higher score than the group without VPS. There was no difference after the third evaluation $(2 \times 3-$ follow-up), indicating that there was no loss of gains two months after the end of treatment for both groups (Figure 3, Table 4).

\section{Timed up and go}

The functional capacity showed a statistically significant improvement for both groups, after the treatment period $(1 \times 2)$. There was no difference after the third evaluation ( $2 \times 3$ - follow-up), indicating that there was no loss of gains two months after the end of the treatment for the group with VPS and the group without VPS (Figure 4, Table 5).

Table 1. Descriptive profile of sociodemographic variables.

\begin{tabular}{|c|c|c|c|}
\hline \multirow{2}{*}{ Groups } & Without VPS $(n=26)$ & With VPS $(n=26)$ & \multirow{2}{*}{$p$-value } \\
\hline & Rate \pm SD & Rate \pm SD & \\
\hline Age (years) & $75.1 \pm 7.7$ & $73.0 \pm 13.5$ & 0.993 \\
\hline Age of disease at disease onset & $73.3 \pm 7.6$ & $71.0 \pm 13.6$ & 0.949 \\
\hline Mini-mental state examination & $17.0 \pm 7.3$ & $20.2 \pm 5.2$ & 0.099 \\
\hline Time of illness & $1.9 \pm 0.9$ & $2.4 \pm 1.3$ & 0.210 \\
\hline Gender & Frequency (\%) & Frequency (\%) & \\
\hline $\mathrm{F}$ & $17(65.4 \%)$ & $13(50.0 \%)$ & 0.400 \\
\hline M & $9(34.6 \%)$ & $13(50.0 \%)$ & \\
\hline \multicolumn{4}{|l|}{ Schooling } \\
\hline Illiterate & $5(19.2 \%)$ & $5(19.2 \%)$ & \\
\hline 1 to 4 years & $15(57.7 \%)$ & $10(38.5 \%)$ & \\
\hline 5 to 8 years & $2(7.7 \%)$ & $4(15.4 \%)$ & \\
\hline 9 to 11 years & $1(3.8 \%)$ & $4(15.4 \%)$ & \\
\hline$\geq 12$ years & $3(11.5 \%)$ & $3(11.5 \%)$ & \\
\hline
\end{tabular}




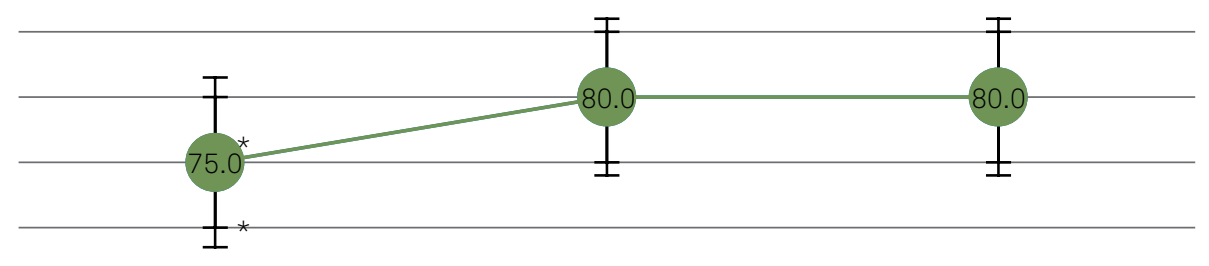

POST_10

POST_18

$\longrightarrow$ Without VPS $\longrightarrow$ With VPS

Legend: median \pm interquartile interval/2.

Figure 1. Data of the three moments of the evaluations and comparison between the groups in relation to the Daily Life Activities.

Table 2. Descriptive analysis and comparisons of activities of daily living at different time points.

\begin{tabular}{|c|c|c|c|c|c|c|}
\hline \multirow{2}{*}{ Group } & \multicolumn{3}{|c|}{ FIM @ } & \multirow{2}{*}{$\begin{array}{l}\text { Friedman test } \\
p \text {-value }\end{array}$} & \multirow{2}{*}{ Multiple comparisons } & \multirow{2}{*}{ Result } \\
\hline & 0 weeks & 10 weeks & 18 weeks & & & \\
\hline \multicolumn{7}{|l|}{ Without VPS } \\
\hline Rate & 70.81 & 72.96 & 73.00 & & $(0 \times 10) p=0.032^{*}$ & \\
\hline Median & 75.00 & 80.00 & 80.00 & $<0.001 *$ & $(0 \times 18) p=0.026^{*}$ & $(0)<(10)=(18)$ \\
\hline Interquartile interval & 30.0 & 30.0 & 22.5 & & $(10 \times 18) p=0.695$ & \\
\hline$n$ & 26 & 26 & 26 & & & \\
\hline \multicolumn{7}{|l|}{ With VPS } \\
\hline Rate & 68.08 & 71.96 & 72.35 & & $(0 \times 10) p=0.003^{*}$ & \\
\hline Median & 75.00 & 80.00 & 80.00 & $<0.001^{\star}$ & $(0 \times 18) p=0.004^{\star}$ & $(0)<(10)=(18)$ \\
\hline Interquartile interval & 42.5 & 32.5 & 32.5 & & $(10 \times 18) p=0.695$ & \\
\hline$n$ & 26 & 26 & 26 & & & \\
\hline Mann-Whitney test $p$-value & 0.707 & 0.934 & 0.942 & & & \\
\hline
\end{tabular}

FIM: Functional Independence Measure scale;VPS: ventriculoperitoneal shunt.

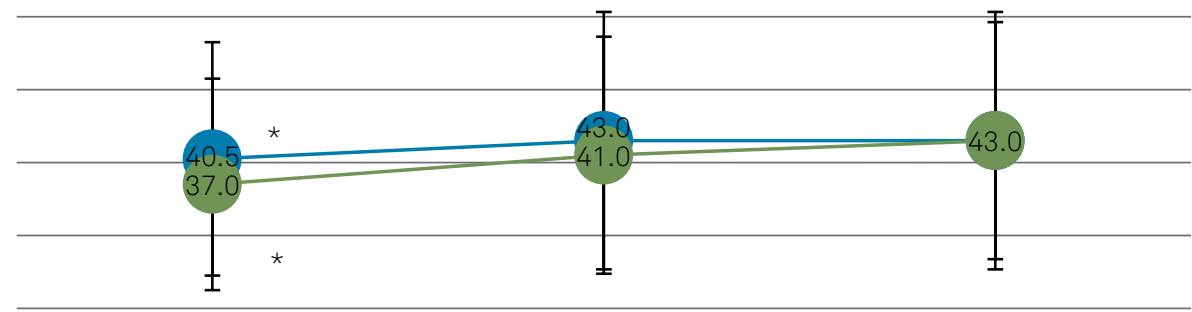

PRE_O

POST_10

POST_18

$\longrightarrow$ Without VPS $\longrightarrow$ With VPS

Legend: median \pm interquartile interval/2.

Figure 2. Data from the three moments of the evaluations and comparison between the groups with respect to the Berg Balance Scale. 
Table 3. Descriptive analysis and comparisons for static balance.

\begin{tabular}{|c|c|c|c|c|c|c|}
\hline \multirow{2}{*}{ Group } & \multicolumn{3}{|c|}{ Berg@ } & \multirow{2}{*}{$\begin{array}{l}\text { Friedman test } \\
p \text {-value }\end{array}$} & \multirow{2}{*}{ Multiple comparisons } & \multirow{2}{*}{ Result } \\
\hline & 0 weeks & 10 weeks & 18 weeks & & & \\
\hline \multicolumn{7}{|l|}{ Without VPS } \\
\hline Rate & 36.1 & 37.9 & 37.9 & & $(0 \times 10) p<0.001 *$ & \\
\hline Median & 40.5 & 43.0 & 43.0 & $<0.001 *$ & $(0 \times 18) p<0.001 *$ & $(0)<(10)=(18)$ \\
\hline Interquartile interval & 32.0 & 35.3 & 35.3 & & $(10 \times 18) p=1.000$ & \\
\hline$n$ & 26 & 26 & 26 & & & \\
\hline \multicolumn{7}{|l|}{ With VPS } \\
\hline Rate & 34.3 & 36.3 & 37.0 & & $(0 \times 10) p<0.001 *$ & \\
\hline Median & 37.0 & 41.0 & 43.0 & $<0.001 *$ & $(0 \times 18) p=0.009 *$ & $(0)<(10)=(18)$ \\
\hline Interquartile interval & 29.0 & 32.5 & 32.5 & & $(10 \times 18) p=0.458$ & \\
\hline$n$ & 26 & 26 & 26 & & & \\
\hline Mann-Whitney test $p$-value & 0.634 & 0.57 & 0.721 & & & \\
\hline
\end{tabular}

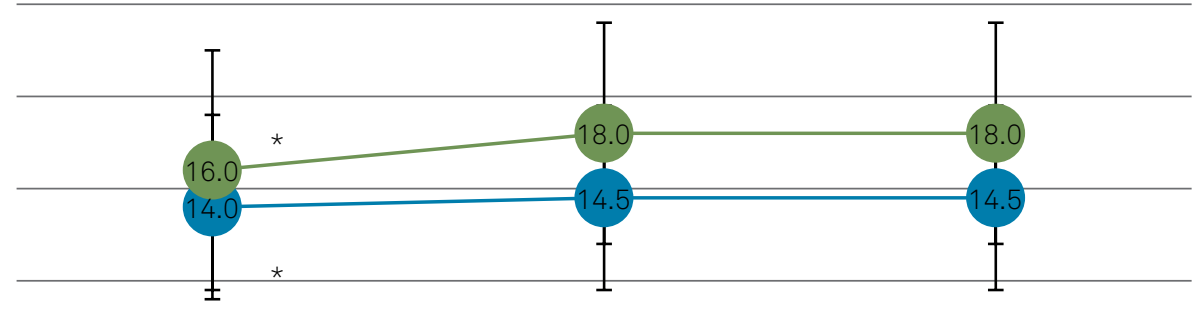

PRE_O

POST_10

POST_18

$\longrightarrow$ Without VPS $\longrightarrow$ With VPS

Legend: median \pm interquartile interval/2.

Figure 3. Data from the three moments of the evaluations and comparison between the groups with respect to the Dynamic Gait Index.

Table 4. Descriptive analysis and comparisons for dynamic balance and gait.

\begin{tabular}{|c|c|c|c|c|c|c|}
\hline \multirow{2}{*}{ Group } & \multicolumn{3}{|c|}{ Gait @ } & \multirow{2}{*}{$\begin{array}{l}\text { Friedman test } \\
\qquad p \text {-value }\end{array}$} & \multirow{2}{*}{ Multiple comparisons } & \multirow{2}{*}{ Result } \\
\hline & 0 weeks & 10 weeks & 18 weeks & & & \\
\hline \multicolumn{7}{|l|}{ Without VPS } \\
\hline Rate & 12.3 & 12.9 & 12.9 & & $(0 \times 10) p=0.009 *$ & \\
\hline Median & 14.0 & 14.5 & 14.5 & $<0.001 *$ & $(0 \times 18) p=0.009 *$ & $(0)<(10)=(18)$ \\
\hline Interquartile interval & 10.0 & 10.0 & 10.0 & & $(10 \times 18) p=1.000$ & \\
\hline $\mathrm{N}$ & 26 & 26 & 26 & & & \\
\hline \multicolumn{7}{|l|}{ With VPS } \\
\hline Rate & 14.0 & 15.3 & 15.3 & & $(0 \times 10) p<0.001 *$ & \\
\hline Median & 16.0 & 18.0 & 18.0 & $<0.001 *$ & $(0 \times 18) p<0.001^{*}$ & $(0)<(10)=(18)$ \\
\hline Interquartile interval & 13.0 & 12.0 & 12.0 & & $(10 \times 18) p=1.000$ & \\
\hline $\mathrm{N}$ & 26 & 26 & 26 & & & \\
\hline Mann-Whitney test $p$-value & 0.340 & 0.158 & 0.158 & & & \\
\hline
\end{tabular}




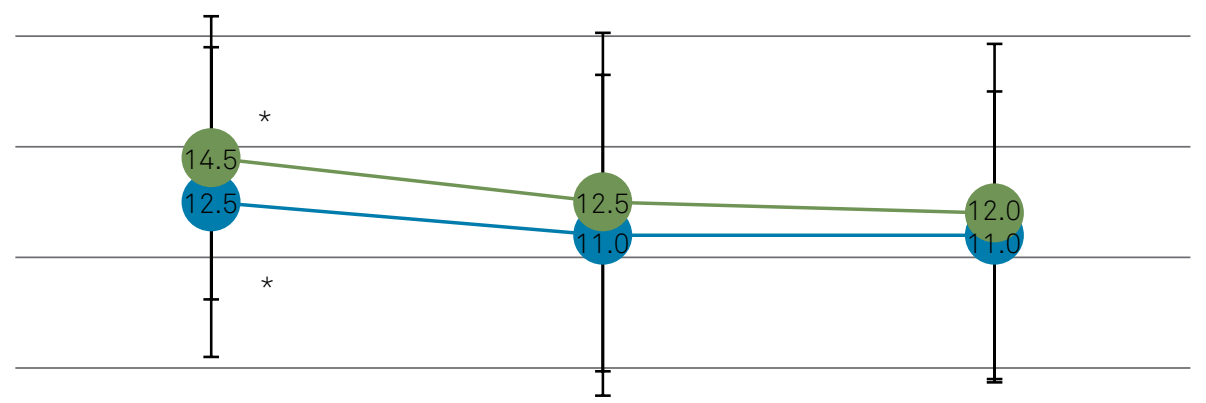

PRE_0

POST_10

POST_18

$\longrightarrow$ Without VPS $\longrightarrow$ With VPS

Legend: median \pm interquartile interval/2.

Figure 4. Data from the three moments of the evaluations and comparison between groups regarding the Timed Up and Go test.

Table 5. Descriptive analysis and comparisons for the Timed Up and Go (TUG).

\begin{tabular}{|c|c|c|c|c|c|c|}
\hline \multirow{2}{*}{ Group } & \multicolumn{3}{|c|}{ TUG@ } & \multirow{2}{*}{$\begin{array}{l}\text { Friedman test } \\
\text { p-value }\end{array}$} & \multirow{2}{*}{ Multiple comparisons } & \multirow{2}{*}{ Result } \\
\hline & 0 weeks & 10 weeks & 18 weeks & & & \\
\hline \multicolumn{7}{|l|}{ Without VPS } \\
\hline Rate & 17.0 & 15.8 & 15.7 & & $(0 \times 10) p<0.001 *$ & \\
\hline Median & 12.5 & 11.0 & 11.0 & $<0.001^{*}$ & $(0 \times 18) p<0.001 *$ & $(0)>(10)=(18)$ \\
\hline Interquartile interval & 12.8 & 15.3 & 15.3 & & $(10 \times 18) p=0.695$ & \\
\hline N & 26 & 26 & 26 & & & \\
\hline \multicolumn{7}{|l|}{ With VPS } \\
\hline Rate & 18.3 & 17.1 & 16.9 & & $(0 \times 10) p=0.027^{*}$ & \\
\hline Median & 14.5 & 12.5 & 12.0 & $<0.001 \star$ & $(0 \times 18) p<0.001 *$ & $(0)>(10)=(18)$ \\
\hline Interquartile interval & 14.0 & 14.5 & 13.0 & & $(10 \times 18) p=0.970$ & \\
\hline N & 26 & 26 & 26 & & & \\
\hline Mann-Whitney test $p$-value & 0.912 & 0.698 & 0.705 & & & \\
\hline
\end{tabular}

VPS: ventriculoperitoneal shunt.

\section{DISCUSSION}

Due to this population needing constant rehabilitation care, physical exercises were chosen, to be carried out at a patient's home, with an efficient and accessible exercise program for this population. Home physical exercises have proven to be a viable alternative for patients who have limited access to health services, especially physiotherapy ${ }^{28}$.

The present study comprised a sample of 52 patients, 26 of whom were submitted for VPS, with a mean age of 74 years. This mean age corroborates data shown in studies in which the mean age of the disease diagnosis was over 65 years old ${ }^{29-31}$.

In this study, there was a predominance of females, with 30 patients (57.7\%) and males, 22 patients (42.3\%), differing from other studies, in which the authors indicated a higher incidence of the disease in males ${ }^{19,32}$.
At the end of 10 weeks of exercises, all the patients who had performed the home physical exercises were questioned about some aspects of the home exercise program: $84.6 \%$ of the patients reported that the program was good; $86.5 \%$ of the patients reported improvements in physical impairments after 10 weeks; and $82.7 \%$ reported no difficulties in performing the exercises. After 18 weeks, the adherence to the program was maintained and there was no difference at the third follow-up evaluation, indicating that there was no loss of gains two months after the end of treatment for both groups.

A study by Kleim and Jones ${ }^{33}$ found that increased physical activity may be a prophylactic vector for maintaining neuroplasticity in brain aging, which can be indexed by functional magnetic resonance and other modern transcranial magnetic stimulation techniques that affect brain aging in relation to cognition. These data corroborate our study because 
our results showed how patients were able to improve their motor skills with 10 weeks of training.

An important concern about home physical exercise programs is related to patient adherence without supervision. Kanas et al. ${ }^{34}$ evaluated home exercises in patients with chronic low back pain for a period of eight weeks, comparing two groups, with and without the supervision of a health professional, but with the help of a booklet, and concluded that the latter was effective for pain improvement, functional capacity and quality of life. The supervision did not significantly influence the final result when comparing the groups ${ }^{34}$. These data corroborate the present study; even with the patients not being personally supervised, they had good adherence to the program and, with the completion of an exercise diary, it was possible to follow the evolution of patients.

Escolar-Reina et al. ${ }^{35}$ studied some characteristics of home exercise programs and concluded that the adherence by the patient was more likely to occur when the approach of healthcare professionals and the content of the exercise program were experienced positively. During our program period, three home visits by the healthcare professional, to evaluate the execution of the exercises and clarify the benefits that the program could bring to their disease, were considered positively by the patients.

Palazzo et al. ${ }^{36}$ also concluded that adherence to this type of program could be facilitated by increasing the attractiveness of the programs, improving patient performance and favoring the feeling of being supported. They found that new technologies met these challenges and seemed attractive to patients, but they did not replace the human relationship between patients and healthcare professionals ${ }^{36}$. In our study, we also tried to improve the feeling of being supported, with weekly telephone calls encouraging the accomplishment of home exercises, and this allowed us to verify that all the patients completed the study, even the elderly and the ones with lower education level.

\section{Study limitations}

A limitation of the present study is the absence of a control group that had no diagnosis of NPH. This may have implied a placebo effect on rehabilitation, since all the patients had NPH. Mendes et al. ${ }^{37}$, in a prospective, observational, casecontrol study, studied the Timed Up and Go test cut-off point for diagnostic confirmation of NPH with 30 patients in the age- and sex-controlled group paired with a group of 30 individuals who had no diagnosis of NPH.

Other limitations were: the reason why there was no improvement of patients with VPS on the quality of life scale may have been because we used the first version of the QoLAlzheimer's Disease scale, where the elderly person evaluated their own QoL. We could have used the second version, where the caregiver or family member evaluated the elderly patient's QoL. With respect to the NPH grading scale, there was no previous training with another sample, and because it was a sensitive scale, no improvement was observed.

\section{CONCLUSION}

The authors of the present study concluded that the home physical exercise program developed was easy to apply and there was good acceptance by most patients with NPH included in the study.

There was a statistically significant improvement after 10 weeks of home physical exercises in the sub-items of activities of daily living, static balance and functional capacity, for both groups.

In the dynamic balance and gait sub-item, there was a statistically significant improvement for both groups but with a higher score for the group with VPS.

There was no statistically significant difference in the sub-items of quality of life, NPH grading scale, and risk of falls, based on the Berg scale.

\section{References}

1. Hakim S, Adams RD. The special clinical problem of symptomatic hydrocephalus with normal cerebrospinal fluid pressure. Observations on cerebrospinal fluid hydrodynamics. J Neurol Sci. $1965 \mathrm{Jul}$ Aug;2(4):307-27. https://doi.org/10.1016/0022-510X(65)90016-X

2. Hebb AO, Cusimano MD. Idiopathic normal pressure hydrocephalus: a systematic review of diagnosis and outcome. Neurosurgery. 2001 Nov;49(5):1166-84.

3. Hakim S. Some observations on CSF pressure: hydrocephalic syndrome in adults with "normal" CSF pressure [Tese]. Bogotá: Universidade Javeriana da Faculdade de Medicina; 1964.

4. Wallenstein MB, McKhann GM 2nd. Salomón Hakim and the discovery of normal-pressure hydrocephalus. Neurosurgery. $2010 \mathrm{Jul}$;67(1):155-9. https://doi.org/10.1227/01.NEU.0000370058.12120.0E

5. Adams RD, Fisher CM, Hakim S, Ojemann RG, Sweet WH. Symptomatic occult hydrocephalus with "normal" cerebrospinalfluid pressure. N Engl J Med. 1965 Jul;273(3):117-26. https://doi.org/10.1056/NEJM196507152730301
6. Vacca V. Diagnosis and treatment of idiopathic normal pressure hydrocephalus. J Neurosci Nurs. 2007 Apr;39(2):107-11. https://doi.org/10.1097/01376517-200704000-00007

7. Marmarou A, Young HF, Aygok GA, Sawauchi S, Tsuji O, Yamamoto $T$, et al. Diagnosis and management of idiopathic normal-pressure hydrocephalus: a prospective study in 151 patients. J Neurosurg. 2005 Jun;102(6):987-97. https://doi.org/10.3171/jns.2005.102.6.0987

8. Hellström P, Edsbagge M, Blomsterwall E, Archer T, Tisell M, Tullberg M, et al. Neuropsychological effects of shunt treatment in idiopathic normal pressure hydrocephalus. Neurosurgery. 2008 Sep;63(3):527-35. https://doi.org/10.1227/01.NEU.0000325258.16934.BB

9. Hashimoto M, Ishikawa M, Mori E, Nobumasa E, Kuwana N. Study of INPH onneurological improvement (SINPHONI). Diagnosis of idiopathic normal pressure hydrocephalus is supported by MRI-based scheme: a prospective cohort study. Cerebrospinal Fluid Res. 2010;31:7-18. 
10. Eide PK, Sorteberg W. Diagnostic intracranial pressure monitoring and surgical management in idiopathic normal pressure hydrocephalus: a 6-year review of 214 patients. Neurosurgery. 2010 Jan;66(1):80-91. https://doi.org/10.1227/01.NEU.0000363408.69856.B8

11. Pinto FC, Saad F, Oliveira MF, Pereira RM, Miranda FL, Tornai $\mathrm{JB}$, et al. Role of endoscopic third ventriculostomy and ventriculoperitoneal shunt in idiopathic normal pressure hydrocephalus: preliminary results of a randomized clinical trial. Neurosurgery. 2013 May;72(5):845-53. https://doi.org/10.1227/NEU.0b013e318285b37c

12. Miranda FL, Tornai JB, Lopes MI. Caracterização da marcha do paciente com hidrocefalia de pressão normal. In: Pinto FCG. Hidrocefalia de pressão normal. São Paulo: Segmento Farma; 2012. p. $85-103$

13. Feick D, Sickmond J, Liu L, Metellus P, Williams M, Rigamonti D, et al. Sensitivity and predictive value of occupational and physical therapy assessments in the functional evaluation of patients with suspected normal pressure hydrocephalus. J Rehabil Med. 2008 Oct;40(9):715-20. https://doi.org/10.2340/16501977-0241

14. Riberto M, Miyazaki MH, Jorge Filho D, Sakamoto H, Battistella LR. Reproductivity brazilian version of functional independence measure. Acta Fisiatr. 2001;8(1):45-52.

15. Riberto M, Miyazaki MH, Jucá SS, Sakamoto H, Pinto PP, Battistella LR. Validation of the Brazilian version of functional independence measure. Acta Fisiatr. 2004;11(2):72-6. https://doi.org/10.5935/0104-7795.20040003

16. Berg K, Wood-Dauphinee S, Williams JI. The Balance Scale: reliability assessment with elderly residents and patients with an acute stroke. Scand J Rehabil Med. 1995 Mar;27(1):27-36.

17. Miyamoto ST, Lombardi Junior I, Berg KO, Ramos LR, Natour J. Brazilian version of the Berg balance scale. Braz J Med Biol Res. 2004 Sep;37(9):1411-21. https://doi.org/10.1590/S0100-879X2004000900017

18. Whitney SL, Hudak MT, Marchetti GF. The dynamic gait index relates to self-reported fall history in individuals with vestibular dysfunction. J Vestib Res. 2000;10(2):99-105

19. Ishikawa M, Hashimoto M, Mori E, Kuwana N, Kazui H. The value of the cerebrospinal fluid tap test for predicting shunt effectiveness in idiopathic normal pressure hydrocephalus. Fluids Barriers CNS. 2012 Jan;9(1):1. https://doi.org/10.1186/2045-8118-9-1

20. VanSwearingen JM, Brach JS. Making geriatric assessment work: selecting useful measures. Phys Ther. 2001 Jun;81(6):1233-52.

21. Mori K. Management of idiopathic normal-pressure hydrocephalus: a multiinstitutional study conducted in Japan. J Neurosurg. 2001 Dec;95(6):970-3. https://doi.org/10.3171/jns.2001.95.6.0970

22. Romão MI. Validação para a Língua Portuguesa da escala de graduação do paciente com hidrocefalia de pressão normal [dissertação]São Paulo: Universidade de São Paulo; 2014.

23. Logsdon RG, Gibbons LE, McCurry SM, Teri L. Assessing quality of life in older adults with cognitive impairment. Psychosom Med. 2002 May-Jun;64(3):510-9. https://doi.org/10.1097/00006842-200205000-00016
24. Novelli MM. Adaptação transcultural da escala de avaliação de qualidade de vida na doença de Alzheimer [Dissertação]. São Paulo: Faculdade de Medicina, Universidade de São Paulo; 2003.

25. Loth EA, Albuquerque CE, Bertolini GRF. Avaliação do Timed Up And Go como preditor de quedas em uma amostra de idosas que relataram queda em 2003. Reabilitar. 2004;1:9-12

26. Kubo Y, Kazui H, Yoshida T, Kito Y, Kimura N, Tokunaga H, et al. Validation of grading scale for evaluating symptoms of idiopathic normal-pressure hydrocephalus. Dement Geriatr Cogn Disord. 2008;25(1):37-45. https://doi.org/10.1159/000111149

27. Laks J, Batista EM, Guilherme ER, Contino AL, Faria ME, Figueira I, et al. [Mini-mental state examination in community-dwelling elderly: preliminary data from Santo Antônio de Pádua, Rio de Janeiro, Brazil]. Arq Neuropsiquiatr. 2003 Sep;61 3B:782-5. Portuguese. https://doi.org/10.1590/S0004-282X2003000500015

28. Nocera J, Horvat M, Ray CT. Effects of home-based exercise on postural control and sensory organization in individuals with Parkinson disease. Parkinsonism Relat Disord. 2009 Dec;15(10):7425. https://doi.org/10.1016/j.parkreldis.2009.07.002

29. Melato L, Bigal ME, Speciali JG. Hidrocefalia de pressão normal: avaliação de cinco anos de experiência e revisão de literatura. Faculdade de Medicina, Ribeirão Preto, 2000; 499-505.

30. Pinto FC. Tratamento cirúrgico da hidrocefalia de pressão normal [tese]. São Paulo: Universidade de São Paulo; 2012.

31. Brean A, Eide PK. Prevalence of probable idiopathic normal pressure hydrocephalus in a Norwegian population. Acta Neurol Scand. 2008 Jul;118(1):48-53. https://doi.org/10.1111/j.1600-0404.2007.00982.x

32. Fernandez PA, Munoz AM, Ortega RE. Hidrocefalia crónica del adulto: análisis descriptivo de 36 casos. Cuad Cir.2006;20(1):43-7. https://doi.org/10.4206/cuad.cir.2006.v20n1-07

33. Kleim JA, Jones TA. Principles of experience-dependent neural plasticity: implications for rehabilitation after brain damage. J Speech Lang Hear Res. 2008 Feb;51(1):S225-39. https://doi.org/10.1044/1092-4388(2008/018)

34. Kanas M, Faria RS, Salles LG, Sorpreso IC, Martins DE, Cunha RA, et al. Home-based exercise therapy for treating non-specific chronic low back pain [online]. Rev Assoc Med Bras (1992). 2018 Sep;64(9):824-31. https://doi.org/10.1590/1806-9282.64.09.824

35. Escolar-Reina P, Medina-Mirapeix F, Gascón-Cánovas JJ, Montilla-Herrador J, Jimeno-Serrano FJ, Sousa SLO, et al. How do care-provider and home exercise program characteristics affect patient adherence in chronic neck and back pain: a qualitative study. BMC Health Serv Res. 2010 Mar;10(1):60. https://doi.org/10.1186/1472-6963-10-60

36. Palazzo C, Klinger E, Dorner V, Kadri A, Thierry O, Boumenir Y, et al. Barriers to home-based exercise program adherence with chronic low back pain: patient expectations regarding new technologies. Ann Phys Rehabil Med. 2016 Apr;59(2):107-13. https://doi.org/10.1016/j.rehab.2016.01.009

37. Mendes GA, Oliveira MF, Pinto FC. The Timed Up Go Test as a diagnostic criterion in normal pressure hydrocephalus. World Neurosurg. 2017 Sep;105(September):456-61. https://doi.org/10.1016/j.wneu.2017.05.137 


\section{APPENDIX}

\section{BOOKLET WITH HOME PHYSICAL EXERCISES FOR PATIENTS WITH NORMAL PRESSURE HYDROCEPHALUS PERFORMED LYING ON THE BED}

\section{EXERCISE 1: STRETCHING (BACK AND GLUTEUS)}

1. Pull both legs against your belly, holding them firmly;

2. Hold and count to 20;

3. Rest and then repeat, counting up to 20 again;

4. Keep the neck RELAXED;

5. Feel the region of the back and gluteus pulling.

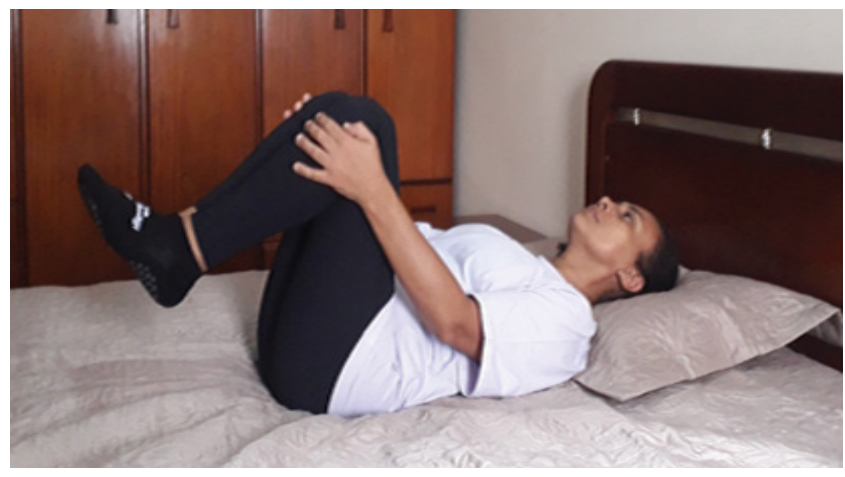

Exercise 1

\section{EXERCISE 2: STRETCHING (TRUNK SIDE REGION)}

1. With knees bent, tilt your legs to the right side and count to 20 ;

2. Then, to the left side and count to 20 ;

3. Keep your shoulders flat on the bed;

4. Rest 30 seconds from one to the other and perform three times for each side.

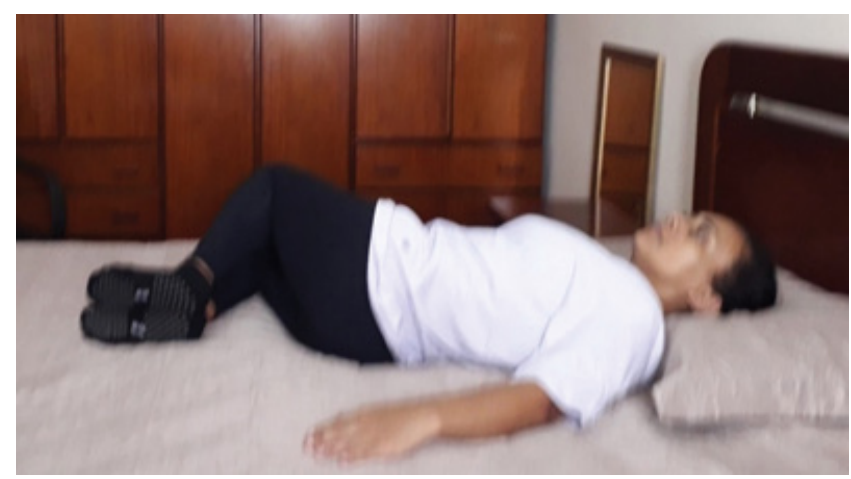

Exercise 2

\section{EXERCISE 3: EXERCISES FOR ALL MOVEMENT (SHOULDER)}

1. Lie on your stomach with your knees bent;

2. Open your arms at shoulder height and turn the palm of your hand upwards;

3. Close your arms with the elbows stretched out as if you were going to clap hands and return the open arms on the bed;

4. Count 20 hand beats, rest one minute and repeat 20 more times.
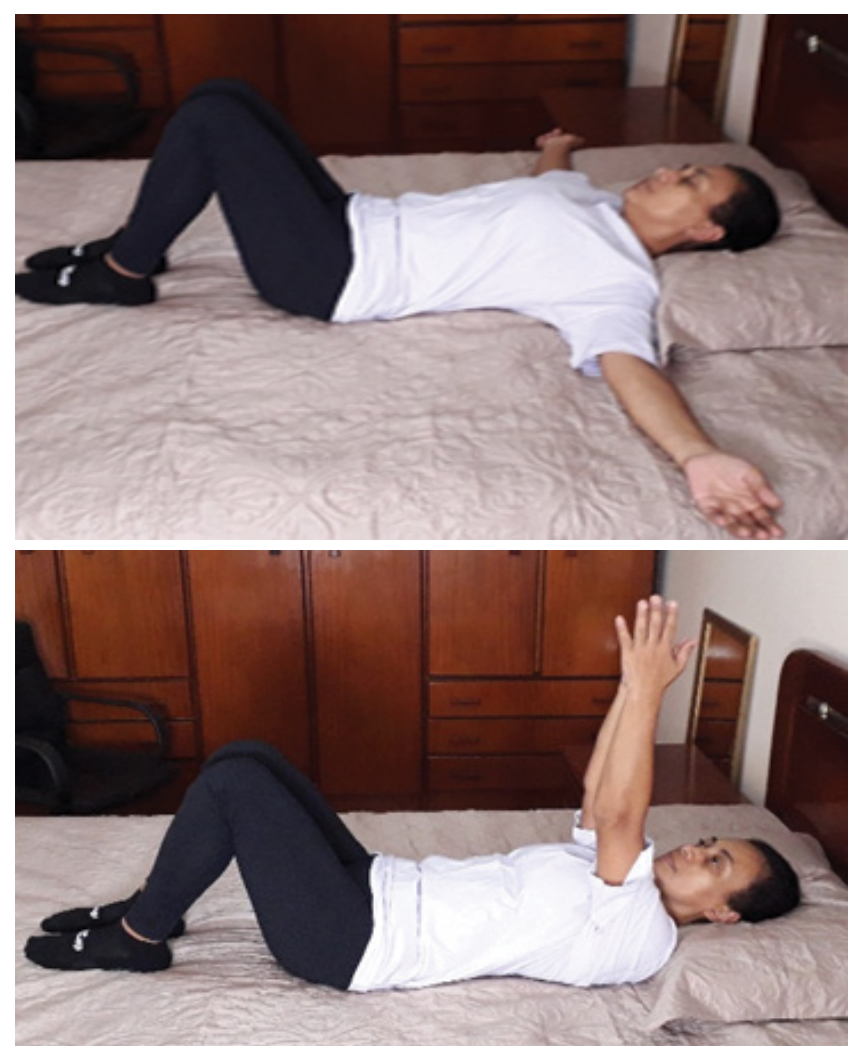

Exercise 3 


\section{EXERCISE 4: STRENGTHENING (ARMS AND LEGS)}

1. Elevate the right arm stretched and touch the left knee with the legs stretched;

2. Count up to 20 alternating legs and arms;

3. Rest one minute and repeat another 20 times;

4. Do with arms and legs stretched.

\section{EXERCISES PERFORMED STANDING}

\section{EXERCISE 5: STRETCHING (ARMS AND LEGS)}

1. Facing a wall, elevate the arms by stretching as much as possible, including standing on the tips of the toes. Imagine that you are stretching to get something that is up high on the wall;

2. Count to 20 and lower your arms to rest;

3. Do one more time counting up to 20 slowly.

\section{EXERCISE 6: BALANCE CARE (RISK OF FALLS)}

1. Leaning yourself against the wall, lift your feet and knees as high as you can, if you feel safer, lean on a stool or ladder;

2. Return to the starting position and change leg. Do 10 repetitions, rest one minute and then do another 10 times.

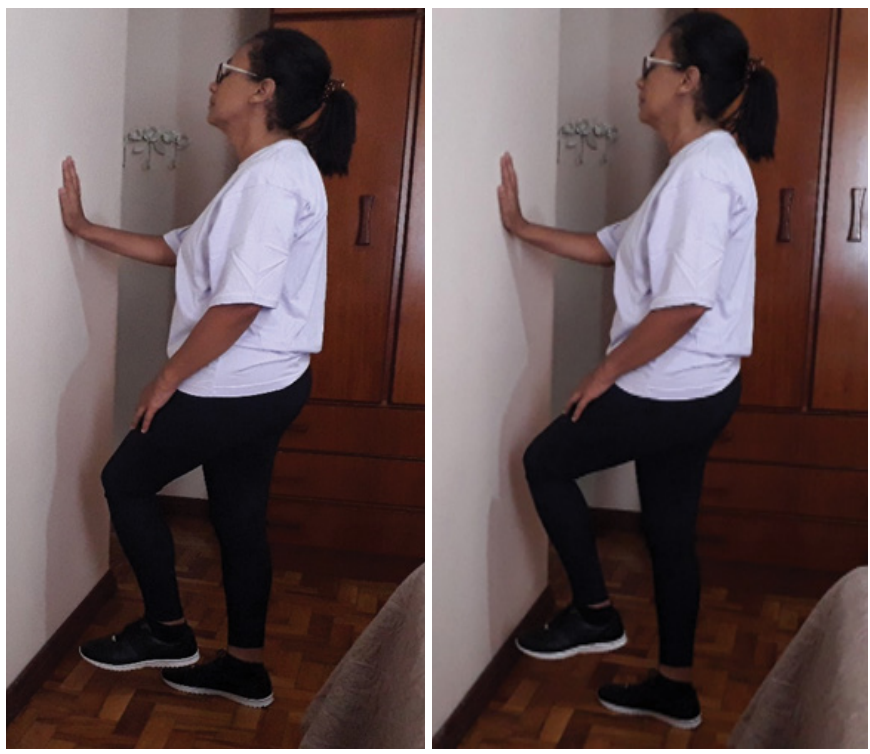

Exercise 6

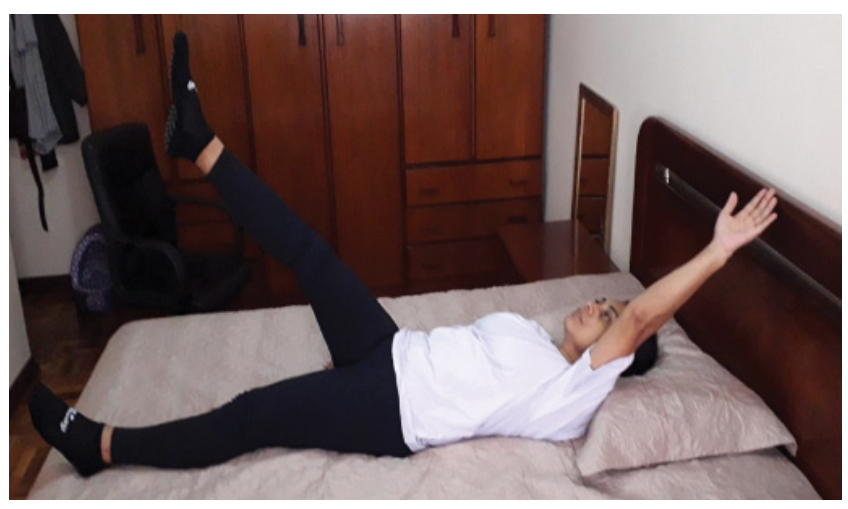

Exercise 4

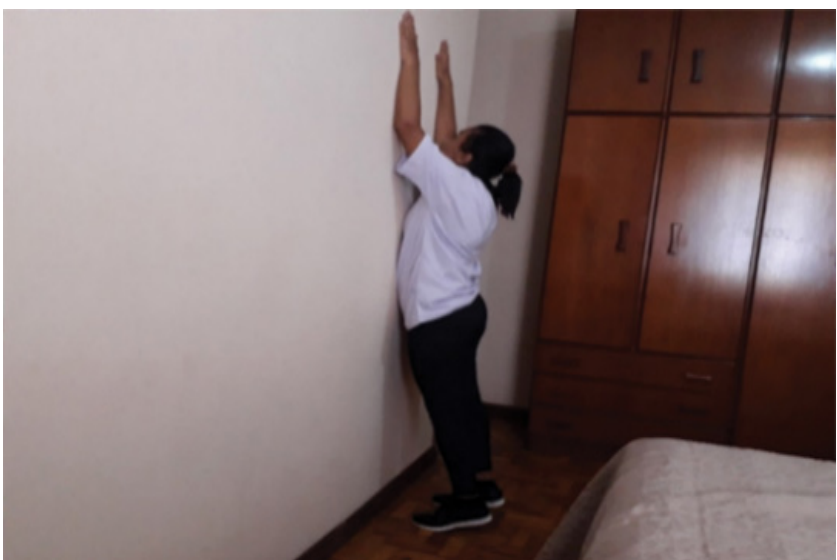

Exercise 5

\section{EXERCISE 7:}

BALANCE CAUTION: IF YOU FEEL UNSTABLE, ASK SOMEONE TO STAY CLOSE TO ASSIST YOU

1. Stand up, raise one knee and hit with the opposite hand. Alternate arms and legs;

2. Perform 10 repetitions, rest one minute and do another 10 times;

3. Remember that if you raise your right knee, you will hit it with your left hand. And if you raise your left knee, you will hit with your right hand.

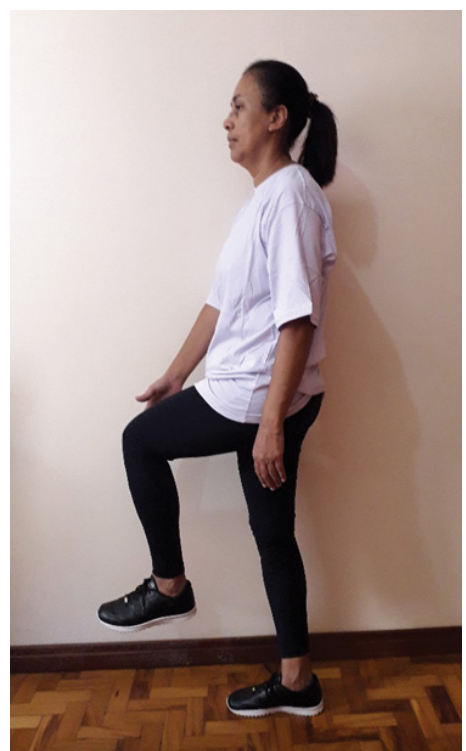

Exercise 7 